\title{
HUBUNGAN SUPERVISI DAN KOMUNIKASI INTERPERSONAL DENGAN PRODUKTIVITAS KERJA PEGAWAI DI BALAI LATIHAN KERJA PENGEMBANGAN INDUSTRI PASAR REBO JAKARTA
}

\author{
Rini Iswanti \\ Karyawan BLKPI Pasar Rebo Jakarta \\ Rini_BPLKI@yahoo.com
}

\begin{abstract}
This study aims to determine the relationship between 1) the supervision of the work ethic, 2) communication with work productivity, and 3) monitoring and communication together with the work ethic. This research was conducted in BLKPI Pasar Rebo, conducted from April to May 2012. The methodology of this study using survey methodology. The study used samples of 92 employees BLKPI Pasar Rebo, and 20 employees on a trial were selected based on a random sample technique (random sampling) to the employee BLKPI Pasar Rebo Jakarta. Data collection techniques using the instrument in the form of a questionnaire. This instrument calibration by using the tool test the validity and reliability coefficients. Test test valliditas using Pearson Product Moment correlation, while the coefficient of reliability was calculated using Cronbach Alpha formula. Results of research in showing that: First, there is a positive relationship between the supervision of the work ethic; Secondly there is a positive relationship between communication with work ethic, and; Thirdly there is a positive relationship between surveillance and communication together with the work ethic. The implication of this study is an effort to improve employee work ethic can be done through monitoring and communication.
\end{abstract}

Keyword: Supervision, Interpersonal Communication, Work Productivity

Abstract: Penelitian ini bertujuan untuk mengetahui hubungan antara 1) pengawasan dengan etos kerja, 2) komunikasi dengan produktivitas kerja, dan 3) pengawasan dan komunikasi secara bersama-sama dengan etos kerja. Penelitian ini dilakukan di BLKPI Pasar Rebo, dilaksanakan dari bulan April sampai dengan Mei 2012. Metodologi penelitian ini menggunakan methodology survey. Penelitian ini memakai sampel 92 pegawai BLKPI Pasar Rebo, dan 20 pegawai sebagai uji coba yang dipilih berdasarkan tehnik sample acak (random sampling) terhadap pegawai BLKPI Pasar Rebo Jakarta. Tehnik pengumpulan data dengan menggunakan instrument dalam bentuk kuesioner. Kalibrasi instrument ini dengan menggunakan alat test koefisien validitas dan reliabilitas. Uji test valliditas dengan menggunakan korelasi Pearson Product Moment, sementara untuk koefisien reliabilitasnya dihitung dengan menggunakan rumus Cronbach Alpha. Hasil penelitian in menunjukkan bahwa: Pertama, terdapat hubungan yang positif antara pengawasan dengan etos kerja; Kedua terdapat hubungan yang positif antara komunikasi dengan etos kerja, dan; Ketiga terdapat hubungan yang positif antara pengawasan dan komunikasi secara bersama-sama dengan etos kerja. Implikasi dari penelitian ini adalah sebuah upaya untuk memperbaiki etos kerja pegawai dapat dilakukan melalui pengawasan dan komunikasi.

Kata kunci: supervisi, komunikasi interpersonal, produktivitas kerja 
Respon terhadap perubahan benar-benar bergantung pada kualitas sumber daya manusia, baik dalam kapasitas individu, keluarga, kelompok masyarakat, maupun sebagai bangsa. Kualitas sumber daya manusia sebagai penentu pembangunan diperlukan pendidikan sebagai ikhtiar sentral yang harus diperhatikan semua pihak. Paradigma klasik mengatakan bahwa pendidikan berkembang untuk membentuk masyarakat yang berkualitas, akan tetapi masyarakatpun berkemampuan membentuk pendidikan yang berkualitas.

Hal inilah yang menjadi salah satu tantangan berat bagi pengelola pendidikan/pelatihan untuk mempersiapkan sumber daya manusia yang berkualitas, cerdas, berakhlak mulia, jujur, terampil dan professional dalam ilmu pengetahuan, teknologi dan kemampuan manajerial yang handal, serta berwawasan ke depan dengan mengingat masa lalu dan masa kini. Sebagai implikasinya terkandung makna link and match yang menekankan bahwa pengelolaan pendidikan/pelatihan harus ditingkatkan dan dikembangkan sesuai dengan tuntutan kebutuhan industri dan kebutuhan

masyarakat, dengan tanpa meninggalkan identitas, norma agama dan budaya luhur bangsa, baik untuk situasi dan kondisi masa kini dan masa yang akan datang.

Pelatihan merupakan pekerjaan profesional, karena lapangan pekerjaan ini menuntut keahlian khusus yang membutuhkan prasyarat dasar, ketrampilan teknis, dan sikap kepribadian. Kebutuhan-kebutuhan tersebut dapat dipenuhi melalui proses pendidikan dan latihan yang berkualitas. Proses tersebut diselenggarakan dalam suatu Balai Latihan Kerja Pengembangan Industri, yaitu suatu lembaga yang bentuk organisasi, program, dan pengelolaannya tertata secara sistemik. Lembaga ini mampu mengembangkan teori maupun praktek pelatihan bagi calon tenaga kerja yang produktif, sehingga lulusannya mampu bersaing dalam dunia kerja.

Balai Latihan Kerja Pengembangan Industri (BLKPI) merupakan institusi pemerintah yang mempunyai tugas melaksanakan tugas pemerintah di bidang pelatihan, tenaga kerja dan perluasan tenaga kerja, dan produktifitas tenaga kerja, pengawasan tenaga kerja. Pengembangan sumber daya manusia dalam suatu organisasi perlu dilakukan untuk meningkatkan kontribusi terhadap pencapaian tujuan organisasi. Hal ini pula yang dilakukan oleh Balai Latihan Kerja Pengembangan Industri terhadap para pegawai. Pengembangan sumber daya manusia dilakukan melalui pelayanan diklat yang diselenggarakan secara berkala.

Sebagai lembaga pelatihan professional yang melaksanakan pelatihan calon tenaga kerja Balai Latihan Kerja Pengembangan Industri harus tanggap terhadap perkembangan masyarakat dan kebutuhannya. Oleh karena itu Balai Latihan Kerja Pengembangan Industri harus selalu siap mengembangkan ilmu dan teknologi pendidikan/pelatihan agar program-program yang dilaksanakan dapat menunjang kualitas kehidupan masyarakat. Kepekaan menanggapi kebutuhan masyarakat merupakan keharusan agar eksistensinya sebagai lembaga profesional penghasil calon tenaga kerja diterima dan mendapat dukungan masyarakat.

Dalam rangka melaksanakan peran dan kewajiban membentuk calon tenaga kerja yang handal dengan baik apabila lembaga yang bersangkutan secara keseluruhan memiliki kondisi yang dinamis untuk mampu bergerak menunjang proses pencapaian tujuan lembaga atau organisasi. Balai Latihan Kerja Pengembangan Industri dituntut meng- gembangkan manajemen kelembagaan yang didasarkan pada prinsipprinsip kepedulian terhadap mutu, inovatif, dedikasi dan dukungan pimpinan. Pengembangan manajemen kelembagaan/organisasi diarahkan untuk meningkatkan kinerja manajemen organisasi/lembaga secara 
menyeluruh, sehingga memiliki kemampuan untuk meningkatkan produktivitas, daya saing, dan mutu layanan organisasi. Untuk mewujudkan tujuan ini, maka fokus pengembangan dipusatkan pada aspek manajerial seluruh unsur pimpinan, sistem supervisi, pengelolaan sumber daya, dan sistem informasi dan komunikasi.

Selain pengembangan manajemen organisasi, Balai Latihan Kerja Pengembangan Industri dituntut selalu melakukan pembaharuan pelatihan, khususnya dalam pengelolaan proses pembelajaran. Komponen penting yang harus dipersiapkan dan dibina untuk melakukan pembaharuan meliputi: kurikulum, sarana, dan pegawai dalam hal ini instruktur.

Instuktur merupakan komponen utama dalam proses pembelajaran dan mempengaruhi hasil belajar. Instruktur yang melatih calon tenaga kerja mempunyai tugas dan tanggung jawab yang lebih besar lagi karena penampilannya akan menjadi contoh bagi peserta pelatihan. Intruktur tidak cukup hanya mempunyai kemampuan teori dan praktek tetapi harus mampu mengaktualisasikan dalam perbuatan dan penampilan dalam kegiatan pembelajaran. Oleh karena itu pegawai/instruktur perlu me- ningkatkan kompetensinya secara terus menerus terutama kompetensi tugas yang berkaitan dengan pekerjaannya, sehingga dengan ke- mampuanya tersebut pegawai dalam menjalankan perannya dengan baik.

Menurut (Sedarmayanti, 2009: 48) Berhasil tidaknya pendidikan memproduksi keluaran yang berkualitas, juga akan ditentukan oleh faktor manusia sebagai sub sistem yang akan turut mewarnai keberhasilan pendidikan dalam meraih mutu lulusan yang lebih baik, yang diharapkan akan merupakan sumber daya manusia yang dibutuhkan dalam mengisi pembangunan jangka panjang. Sumber daya manusia diharapkan akan mampu meningkatkan kualitas hidupnya melalui suatu proses pendidikan, latihan dan pengembangan yang akan menjamin kinerja dan produktivitas kerja agar semakin meningkat.

Berdasarkan uraian di atas diharapkan pegawai/instruktur dapat menunjukkan produktivitasnya dengan baik. Untuk dapat menjalankan perannya dengan baik instruktur tetap membutuhkan bantuan-bantuan yang dapat mendukung peningkatan produktivitasnya. Dalam hal ini Kepala Balai Latihan Kerja Pengembangan Industri merupakan penanggung jawab terhadap manajemen lembaga, memiliki tugas membantu para pegawai untuk mengembangkan kesanggupan- kesanggupan mereka secara maksimal dalam membangun produktivitas kerjanya dan menciptakan suasana kantor yang sehat. Kepala BLKPI sebagai supervisor yang memberikan peluang, fasilitas, dan dorongan terhadap instruktur untuk menunjukkan kinerja terbaiknya sangat dibutuhkan oleh pegawai/instruktur dalam bekerja dengan baik sehingga dapat meraih produktivitasnya dengan optimal.

Dalam rangka pembinaan dan pengembangan kemampuan, keterampilan, sikap, motivasi dan perilaku maka perlu dilakukan penilaian atas pekerjaan yang telah dilaksanakan oleh pegawai. Penilaian pelaksanaan pekerjaan merupakan suatu sistem yang digunakan untuk menilai hasil fisik yang telah dihasilkan oleh pegawai. Pelaksanaan pekerjaan meliputi berbagai aspek seperti: kemampuan kerja, kerajinan, disiplin, hubungan kerja, dan lain-lain sesuai dengan tugas dan kewajiban yang telah ditentukan. Hal tersebut diharapkan dapat menunjukkan produktivitas kerja para pegawai secara teratur dan rutin, sehingga bermanfaat bagi pengembangan produktivitas kerja pegawai yang dinilai maupun lembaga secara keseluruhan. Untuk menghadapi globalisasi diperlukan kemampuan sumber daya manusia dan kelembagaan, baik di sektor swasta. Sumber daya manusia yang bermutu tersebut memiliki keimanan dan ketakwaan serta menguasai ilmu, 
pengetahuan dan teknologi, memiliki etos kerja dan mampu membangun budaya kerja yang produktif.

Menurut Akhyar Efendi (2009: 36) dalam jurnal Manajemen PNS yang efektif bahwa dari segi kualitas sumber daya manusia, profil PNS memperhatikan masih rendahnya kualitas, kapasitas dan mentalitas PNS sebagai akibat dari rendahnya rasionalitas dan keterkaitan antara sub sistem dalam manajemen PNS. Permasalahan kinerja dan profesiomalisme kinerja PNS selalu menjadi sorotan banyak pihak. Lebih lanjut menurut Latief (2002: 58) etos kerja bangsa Indonesia relatif masih nrendah antara lain tercermin dari disiplin, semangat kerjaan, produktivitas yang rendah. Produktivitas kerja pegawai merupakan hal yang menarik untuk dikaji lebih lanjut, meski banyak faktor yang perlu diperhatikan namun faktor supervisi dan komunikasi interpersonal dianggap merupakan faktor yang paling dominan untuk dianalisis. Supervisi sangat berperan dalam membina pegawai untuk meningkatkan kualitas kerja, sehingga produktivitas akan meningkat. Demikian juga komunikasi interpersonal yang berkaitan sangat besar bagi setiap pegawai dalam menjalankan tugasnya dengan baik.

Dari uraian di atas, menarik untuk dikaji lebih lanjut mengenai hubungan supervisi dan komunikasi interpersonal dengan produktivitas kerja pegawai Balai Latihan Kerja Pengembangan Industri Pasar Rebo, Jakarta.

\section{METODE}

Penelitian ini menggunakan metode survey, dengan teknik kore- lasional dengan cara mengumpulkan data melalui instrumen. Metode tersebut digunakan untuk menguji hubungan antara dua variabel bebas dengan satu variabel terikat. Dalam penelitian ini terdapat dua variabel bebas, yaitu supervisi (X1), dan komunikasi interpersonal (X2), sedangkan variabel terikatnya adalah produktivitas kerja (Y). Hubungan dalam variabel terikat dan variabel bebas penelitian digambarkan dalam bentuk konstelasi hubungan antar variabel seperti gambar berikut :

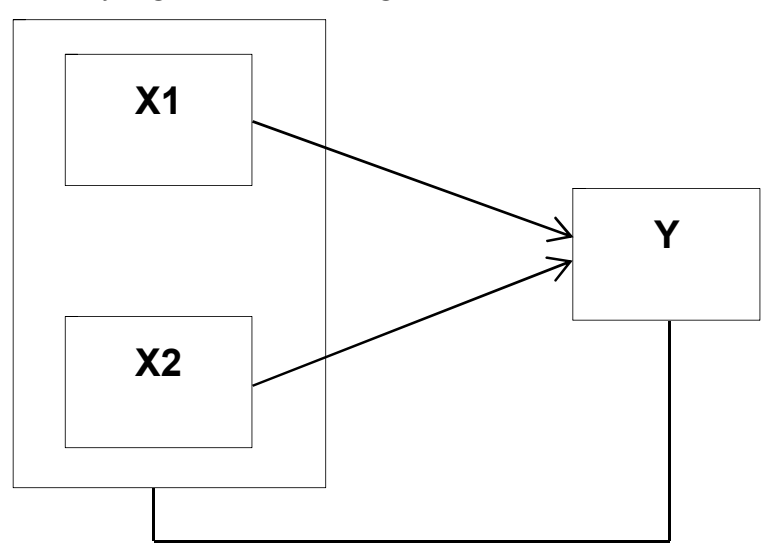

Gambar 3.1 Konstelasi Hubungan antara Variabel Penelitian

Keterangan:
$\mathrm{X} 1$ : Supervisi
X2 : Komunikasi Interpersonal
Y : Produktivitas Kerja 
HASIL

\section{Skor Produktivitas Kerja}

Hasil pengambilan data lapangan untuk Produktivitas Kerja mempunyai nilai tertinggi 125 dan terendah 70 dengan rentangan nilai 55. Dari hasil perhitungan statistik diperoleh nilai rata-rata sebesar 97,3043 , median $=96$, modus $=87$, standar deviasi $=13,498$ dan varians sebesar 182,192. Banyak kelas yang diperoleh dalam penelitian ini terdiri dari tujuh kelas dengan panjang kelas delapan.

\section{Skor Supervisi}

Berdasarkan data yang diperoleh, skor untuk Supervisi mempunyai nilai tertinggi 120 dan terendah 72 dengan rentangan nilai 48 dari hasil perhitungan statistik diperoleh nilai rata-rata sebesar 94,913 median $=94$ modus $=94$, standar deviasi $=13,196$ dan varians
Distribusi skor frekuensi Produktivitas Kerja secara keseluruhan dapat dilihat pada Tabel 4.1. di bawah ini:

\section{Tabel 4.1: Distribusi Frekuensi Produktivitas Kerja}

frekuens frekuensi no kelas interval frekuensi i relatif kumulatif

\begin{tabular}{ccccc} 
& & & $(\%)$ & $(\%)$ \\
\hline 1 & $70-77$ & 9 & $9,78 \%$ & $9,78 \%$ \\
\hline 2 & $78-85$ & 8 & $8,70 \%$ & $18,48 \%$ \\
\hline 3 & $86-93$ & 26 & $28,26 \%$ & $46,74 \%$ \\
\hline 4 & $94-101$ & 13 & $14,13 \%$ & $60,87 \%$ \\
\hline 5 & $102-109$ & 18 & $19,57 \%$ & $80,43 \%$ \\
\hline 6 & $110-117$ & 8 & $8,7 \%$ & $89,13 \%$ \\
\hline 7 & $118-125$ & 10 & $10,87 \%$ & $100,00 \%$ \\
\hline & Jumla & 9 & $100 \%$ & \\
& h & 2 & &
\end{tabular}
sebesar 174,124. Banyak kelas yang diperoleh dalam penelitian ini terdiri dari tujuh kelas dengan panjang kelas tujuh. Distribusi skor frekuensi Supervisi secara keseluruhan dapat dilihat pada Tabel 4.2 di bawah ini:

Tabel 4.2: Distribusi Frekuensi Supervisi

\begin{tabular}{|c|c|c|c|c|}
\hline NO & KELAS INTERVAL & FREKUENSI & $\begin{array}{r}\text { FREKUENSI } \\
\text { RELATIF (\%) }\end{array}$ & $\begin{array}{r}\text { FREKUENSI } \\
\text { KUMULATIF (\%) }\end{array}$ \\
\hline 1 & $72-78$ & 10 & $10,87 \%$ & $10,87 \%$ \\
\hline 2 & $79-85$ & 17 & $18,48 \%$ & $29,35 \%$ \\
\hline 3 & $86-92$ & 11 & $11,96 \%$ & $41,30 \%$ \\
\hline 4 & $93-99$ & 20 & $21,74 \%$ & $63,04 \%$ \\
\hline 5 & $100-106$ & 14 & $15,22 \%$ & $78,26 \%$ \\
\hline 6 & $107-113$ & 10 & $10,87 \%$ & $89,13 \%$ \\
\hline 7 & $114-120$ & 10 & $10,87 \%$ & $100,00 \%$ \\
\hline & Jumlah & 92 & $100 \%$ & \\
\hline
\end{tabular}

\section{Skor Komunikasi Interpersonal}

Berdasarkan data yang diperoleh, skor untuk Komunikasi Interpersonal memperoleh nilai tertinggi 120 dan terendah 65 dengan rentangan nilai 55dan hasil perhitungan statistik diperoleh nilai rata- rata sebesar 99,174, median $=101$, modus $=95$, standar deviasi $=11,655$ dan varians sebesar
135,838. Banyak kelas yang diperoleh dalam penelitian ini terdiri dari tujuh kelas dengan panjang delapan. Distribusi skor frekuensi Lingkungan Kerja secara keseluruhan dapat dilihat pada Tabel 4.3 di bawah ini: 
Tabel 4.3: Distribusi Frekuensi Komunikasi Interpersonal

\begin{tabular}{ccccc} 
NO & KELAS INTERVAL & FREKUENSI & $\begin{array}{c}\text { FREKUENSI } \\
\text { RELATIF\% }\end{array}$ & $\begin{array}{c}\text { FREKUENSI } \\
\text { KUMULATIF } \\
\text { (1 } ~\end{array}$ \\
\hline 1 & $65-72$ & 1 & $1,09 \%$ & $1,09 \%$ \\
\hline 3 & $73-80$ & 5 & $5,43 \%$ & $6,52 \%$ \\
\hline 4 & $81-88$ & 11 & $11,96 \%$ & $18,48 \%$ \\
\hline 5 & $89-96$ & 18 & $19,57 \%$ & $38,04 \%$ \\
\hline 6 & $105-112$ & 24 & $26,09 \%$ & $64,13 \%$ \\
\hline 7 & $113-120$ & 23 & $25.00 \%$ & $89,13 \%$ \\
\hline & Jumlah & 10 & $10,87 \%$ & $100,00 \%$ \\
\hline
\end{tabular}

Pengujian persyaratan analisis yang dimaksud adalah persyaratan yang harus dipenuhi agar analisis regresi dapat dilakukan, baik untuk keperluan prediksi maupun untuk keperluan pengujian hipotesis. Ada tiga syarat yang harus dipenuhi sebelum melakukan analisis regresi, baik regresi linier sederhana maupun regresi ganda, yaitu: pertama, syarat normalitas galat taksiran $(\hat{\mathrm{Y}}-\mathrm{Y})$ dari suatu regresi sederhana; kedua, syarat homogenitas varians kelompok-kelompok skor Y yang dikelompokkan berdasarkan kesamaan data variabel prediktor $\left(\mathrm{X}_{\mathrm{i}}\right)$; dan ketiga, syarat kelinieran untuk regresi $\mathrm{Y}$ atas $\mathrm{X}_{\mathrm{i}}$ untuk regresi sederhana.

Dari ketiga persyaratan tersebut ada dua persyaratan yang disajikan pengujiannya pada bagian ini, yaitu uji persyaratan normalitas galat taksiran regresi $\mathrm{Y}$ atas $\mathrm{X}_{\mathrm{i}}$ dan uji persyaratan homogenitas varians kelompok-kelompok skor $\mathrm{Y}$ berdasarkan kesamaan data $\mathrm{X}$, sedangkan uji kelinieran bentuk regresi sederhana $\mathrm{Y}$ atas $\mathrm{Xi}$ akan diuji pada bagian pengujian hipotesis penelitian.

\section{Uji Normalitas Galat Taksiran}

Pengujian normalitas galat taksiran regresi $\mathrm{Y}$ atas X1, X2, dimaksudkan untuk menguji apakah populasi berdistribusi normal atau tidak. Ketentuan pengujiannya adalah galat taksiran $(\hat{\mathrm{Y}}-\mathrm{Y})$ berdistribusi normal jika Ho diterima dan tidak berdistribusi normal jika $\mathrm{H}_{0}$ ditolak.

$\mathrm{H} 0=$ Data berasal dari populasi berdistribusi normal

H1 = Data berasal dari populasi tidak berdistribusi normal

Pengujian persyaratan normalitas galat taksiran variabel terikat terhadap variabel bebas dilakukan dengan menggunakan uji Lilliefors dengan kriteria uji:

$\mathrm{H} 0=$ diterima, jika Lhitung $<$ Ltabel

$\mathrm{H}_{0}=$ ditolak, jika Lhitung $>$ Ltabel

\section{Uji Normalitas Galat Taksiran Regresi Y atas X1}

Pertama-tama dihitung persamaan regresi $\mathrm{Y}$ atas $\mathrm{X}_{1}$. Selanjutnya dicari nilai $\hat{\mathrm{Y}}_{\mathrm{i}}$ untuk setiap $\mathrm{X}_{\mathrm{i}}$. Kemudian dicari $\mathrm{Y}$ galat $(\hat{\mathrm{Y}}-\mathrm{Y})$ berdasarkan pasangan data tersebut. Selanjutnya dihitung nilai $\mathrm{zi}, \quad \mathrm{F}(\mathrm{zi}), \quad \mathrm{S}(\mathrm{zi})$ dan $\mathrm{L}=\mathrm{F}(\mathrm{zi})-\mathrm{S}(\mathrm{zi})$. Lhitung diambil dari nilai $\mathrm{L}$ tertinggi.

Berdasarkan analisis regresi diperoleh persamaan regresi $\hat{\mathrm{Y}}=44,326+0,558 \mathrm{X} 1$. Untuk selanjutnya dilakukan perhitungan dengan menggunakan bantuan program excel for windows, sehingga diperoleh nilai-nilai $\mathrm{L}$ hitung tertinggi = 0,041 dan $\mathrm{L}$ tabel $=0,092$. Dengan demikian karena $\mathrm{L}$ hitung $(0,041)<\mathrm{L}$ tabel $(0,092)$, maka dapat disimpulkan $\hat{\mathrm{Y}}$ galat dengan persamaan $\hat{\mathrm{Y}}=44,326$ $+0,558$ X1 mempunyai distribusi yang normal. 
Hubungan Supervisi Dan Komunikasi Interpersonal Rini Iswanti

Uji Normalitas Galat Taksiran Regresi Y atas X2

Berdasarkan analisis regresi diperoleh persamaan regresi $\hat{Y}=51,42+0,463$ X2. Untuk selanjutnya dilakukan perhitungan dengan menggunakan bantuan program excel for windows, sehingga diperoleh nilai-nilai $\mathrm{L}$ hitung tertinggi = 0,040 dan $\mathrm{L}$ tabel $=0,092$. Dengan demikian karena L hitung $(0,040)>\mathrm{L}$ tabel $(0,092)$, maka dapat disimpulkan $\hat{Y}$ galat dengan persamaan regresi $\hat{Y}=$ $51,42+0,31463 \mathrm{X}_{2}$ mempunyai distribusi yang normal.

Secara ringkas hasil pengujian persayaratan normalitas galat taksiran dapat dilihat pada Tabel 4.4. berikut:

Tabel 4.4. Rangkuman Analisa Uji Normalitas Galat Taksiran

\begin{tabular}{ccccc}
$\begin{array}{c}\text { Galat Taksiran } \\
\text { Regresi Y atas }\end{array}$ & $\mathrm{n}$ & Lhitung & $\mathrm{L}$ tabel $(\alpha=0,05)$ & Keterangan \\
\hline $\mathrm{X} 1$ & 92 & 0,042 & 0,092 & Normal \\
\hline $\mathrm{X} 2$ & 92 & 0,040 & 0,092 & Normal
\end{tabular}

Keterangan :

$$
\begin{array}{ll}
\mathrm{Y} & =\text { Produktivitas Kerja } \\
\mathrm{X} 1 & =\text { Supervisi } \\
\mathrm{X} 2 & =\text { Komunikasi Interpersonal } \\
\mathrm{n} & =\text { Banyak sampel }
\end{array}
$$

\section{Pengujian Hipotesis Penelitian}

\section{Hubungan antara Supervisi dengan Produktivitas}

\section{Kerja}

Hipotesis pertama menyatakan terdapat hubungan positif antara supervisi dengan produktivitas kerja yang ditunjukkan dalam persamaan regresi $\hat{\mathrm{Y}}=$ $44,326+0,558 \mathrm{X} 1$. Uji signifikansi dan kelinieran

\begin{tabular}{|c|c|c|c|c|c|c|}
\hline $\begin{array}{l}\text { Sumber } \\
\text { Varians }\end{array}$ & dk & $\mathbf{J K}$ & RJK & Fhitung & $\begin{array}{l}\mathrm{Ft}= \\
<=0,05\end{array}$ & $\begin{array}{l}F t= \\
<=0,01\end{array}$ \\
\hline Total & 92 & 887.648 & & & & \\
\hline Koefisien (a) & 1 & $871.068,552$ & & \multirow[b]{3}{*}{$38,145 * *$} & \multirow[b]{3}{*}{3,95} & \multirow[b]{3}{*}{6,85} \\
\hline Regresi (b/a) & 1 & $4.935,195$ & $4.935,195$ & & & \\
\hline Sisa & 90 & $11.644,253$ & 129,38 & & & \\
\hline Tuna Cocok & 34 & $1.883,753$ & 55,404 & \multirow{2}{*}{$\mathbf{0 , 3 1 7 9}{ }^{\mathrm{ns}}$} & \multirow{2}{*}{1,63} & \multirow{2}{*}{2,01} \\
\hline Galat & 56 & $9.760,5$ & 174,294 & & & \\
\hline
\end{tabular}
regresi tersebut tercantum dalam Tabel 4.6. sebagai berikut:

Tabel 4.5. Tabel ANAVA Untuk Uji Signifikansi dan Linieritas Regresi $\hat{Y}=44,326+0,558$ X1

Keterangan:

$* * \quad=$ Regresi sangat signifikan, Fhitung $>$ Ftabel, pada $\alpha=0,01(38,145>6,85$

ns $\quad=$ Non-signifikan, regresi berbentuk linier, Fhitung $<$ Ftabel pada $\alpha=\mathbf{0 , 0 5}(0,3179<1,63)$

$\mathrm{Dk}=$ Derajat Kebebasan

JK = Jumlah Kuadrat

RJK = Rata-rata Jumlah Kuadrat

Berdasarkan pada tabel di atas dapat dilihat bahwa Fhitung model regresi seherhana sebesar 38,145 < produktivitas kerja dan supervisi yang digambarkan sebesar 6,85. Kesimpulannya bentuk hubungan antara melalui persamaan regresi $\hat{Y}=44,326+0,558 \mathrm{X} 1$ adalah sangat signifikan. Selanjutnya nilai Fhitung 
Tuna Cocok sebesar $0,3179<$ Ftabel pada $\sqsupset=0,05$ sebesar 1,63, maka dapat disimpulkan bahwa bentuk regresi sederhana produktivitas kerja dan kupervisi yang digambarkan dalam persamaan regresi sederhana $\hat{\mathrm{Y}}=44,326+0,558 \mathrm{X} 1$ adalah linier.

Dari persamaan regresi tersebut disimpulkan bahwa setiap kenaikan satu satuan supervisi akan diikuti dengan kenaikan produktivitas kerja sebesar 0,558 satuan pada konstanta 44,326. Kekuatan hubungan antara supervisi dengan produktivitas kerja , ditentukan oleh koefisien korelasi ryl sebesar 0,549 dengan nilai t-hitung $(6,23)>\mathrm{t}$ tabel $(2,63)$ pada $\alpha=$ 0,01. Berdasarkan uji signifikansi koefisien korelasi tersebut dapat disimpulkan bahwa koefisien korelasi antara supervisi dengan produktivitas kerja sebesar 0,549 sangat signifikan. Dengan demikian dikukuhkan hipotesis yang menyatakan terdapat hubungan positif antara supervisi dengan produktivitas kerja telah terbukti. Artinya, makin tinggi supervisi maka

produktivitas kerja makin baik. Koefisien determinasinya adalah $\mathrm{r}^{2} \mathrm{y} 1=(0,549)^{2}=0,301$ atau $30,1 \%$. Dengan koefisien determinasi 0,301 atau $30,1 \%$ menunjukkan bahwa supervisi memberikan kontribusi terhadap produktivitas kerja sebesar 30,1\%.

Dengan mengontrol pengaruh variabel komunikasi interpersonal didapatkan korelasi parsial antara supervisi dan produktivitas kerja, yaitu $\mathrm{r}$ y1.2 $=0,549$. Uji keberartian korelasi parsial diperoleh harga thitung sebesar 4,87 dan harga tabel sebesar 1,95 pada $\alpha=0,05$. Karena t-hitung $(4,87)>$ t-tabel $(1,95)$, maka disimpulkan bahwa koefisien korelasi parsial signifikan.

Tabel 4.6. Uji Signifikansi Koefisien Korelasi antara Supervisi dengan Produktivitas Kerja

\begin{tabular}{ccccc}
\multirow{2}{*}{ Sumber } & \multirow{2}{*}{ Koefisien Korelasi } & thitung & \multicolumn{2}{c}{ tabel } \\
\cline { 4 - 5 } & & & $\alpha=0,05$ & $\alpha=0,01$ \\
\hline$r_{y} 1$ & 0,549 & $6,23^{* *}$ & 1,95 & 2,64 \\
\hline$r_{y} 1.2$ & 0,459 & $4,87^{* *}$ & 1,95 & 2,64
\end{tabular}

Keterangan:

$* *=$ Regresi sangat signifikan, t-hitung $>$ t-tabel pada $\alpha=0,01(6,23>2,64), t$-hitung $>$ t-tabel pada $\alpha=0,01(4,87>$

\section{Hubungan Antara Komunikasi Interpersonal dengan Produktivitas Kerja}

Hipotesis kedua menyatakan terdapat hubungan positif antara komunikai interpersonal dengan produktivitas kerja ditunjukkan dalam persamaan regresi $\hat{\mathrm{Y}}=51,42+0,463 \mathrm{X} 2$. Uji signifikansi dan kelinieran regresi tersebut tercantum dalam Tabel 4.7. sebagai

berikut:

Tabel 4.7. Tabel ANAVA Untuk Uji Signifikansi dan Linieritas Regresi $\hat{Y}=51,42+0,463 \quad X 2$

\begin{tabular}{|c|c|c|c|c|c|c|}
\hline $\begin{array}{l}\text { Sumber } \\
\text { Varians }\end{array}$ & dk & JK & RJK & Fh & $\begin{array}{l}\mathbf{F t}= \\
0,05\end{array}$ & $\begin{array}{l}\mathbf{F t}= \\
0,01\end{array}$ \\
\hline Total & 92 & 887.648 & & & & \\
\hline Koefisien (a) & 1 & $871.068,522$ & & & & \\
\hline Regresi (b/a) & 1 & $2.647,958$ & $2.647,958$ & $17,062 * *$ & 3,95 & 6,85 \\
\hline Sisa & 90 & $13.931,52$ & 154,795 & & & \\
\hline Tuna Cocok & 42 & $6.362,22$ & 151,481 & $0,96^{\mathrm{ns}}$ & 1,62 & 1,90 \\
\hline Galat & 48 & $7.569,3$ & 157,693 & & & \\
\hline
\end{tabular}


Keterangan:

$* * \quad=$ Regresi sangat signifikan, Fhitung $>$ Ftabel, pada $\alpha=0,01(17,062>6,85$

ns $\quad=$ Non-signifikan, regresi berbentuk linier, Fhitung $<$ Ftabel pada $\alpha=\mathbf{0 , 0 5}(0,96<1,62)$

$\mathrm{dk} \quad=$ Derajat Kebebasan

JK = Jumlah Kuadrat

RJK = Rata-rata Jumlah Kuadrat

Berdasarkan pada tabel di atas dapat dilihat bahwa Fhitung model regresi seherhana sebesar 17,062> sebesar 6,85. Kesimpulannya bentuk hubungan antara produktivitas kerja dan komunikasi interpersonal yang digambarkan melalui persamaan regresi $\hat{\mathrm{Y}}=51,42+$ $0,463 \mathrm{X}_{2}$ adalah sangat signifikan. Selanjutnya nilai Fhitung Tuna Cocok sebesar 0,96< F-tabel pada $\alpha$ $=0,05$ sebesar 1,6, maka dapat disimpulkan bahwa bentuk regresi sederhana produktivitas kerja dan komunikasi interpersonal yang digambarkan dalam persamaan regresi sederhana $\hat{Y}=51,42+0,463$ X2 adalah linier.

Dari persamaan regresi tersebut mengandung arti bahwa setiap kenaikan satu satuan unit komunikasi interpersonal diikuti dengan kenaikan produktivitas kerja sebesar 0,463 satuan pada konstanta 51,42.

Kekuatan hubungan antara komunikasi interpersonal dengan produktivitas kerja, ditentukan oleh koefisien korelasi ry2 sebesar 0,415 dengan nilai t-hitung $(4,33)>$ t-tabel $(2,63)$ pada $\alpha=0,01$. Berdasarkan uji signifikansi koefisien korelasi tersebut dapat disimpulkan bahwa koefisien korelasi antara komunikasi interpersonal dengan produktivitas kerja sebesar 0,415 sangat signifikan. Dengan demikian hipotesis yang menyatakan terdapat hubungan positif antara komunikasi interpersonal dengan produktivitas kerja terbukti kebenarannya. Hal ini dapat mengandung makna bahwa, makin baik dan inten komunikasi maka tinggi pula produktivitas kerja pegawai.

Koefisien determinasinya adalah $\mathrm{r}_{\mathrm{y} 2}^{2}=(0,415)^{2}=$ 0,172 atau $17,2 \%$. Dengan koefisien determinasi 0,172 atau $17,2 \%$ menunjukkan bahwa komunikasi interpersonal memberikan kontribusi kepada produktivitas kerja sebesar 17,2\%. Apabila dengan mengontrol pengaruh supervisi didapatkan korelasi parsial antara komunikasi interpersonal dan produktivitas kerja, yaitu $\mathrm{r}$ y2.1 $=0,333$. Uji keberartian korelasi parsial diperoleh harga thitung sebesar 3,34 dan harga ttabel sebesar 1,95 pada $\alpha=$ 0,05. Karena t-hitung $(3,34)>\mathrm{t}$-tabel $(1,95)$, maka disimpulkan bahwa koefisien korelasi parsial signifikan. Secara ringkas hasil perhitungan dan uji signifikansi korelasi dapat dilihat pada tabel berikut:

Tabel 4.8. Uji Signifikansi Koefisien Korelasi antara Komunikasi Interpersonal dengan Produktivitas Kerja

\begin{tabular}{|c|c|c|c|c|}
\hline \multirow{2}{*}{ Sumber } & \multirow{2}{*}{$\begin{array}{l}\text { Koefisien } \\
\text { Korelasi }\end{array}$} & \multirow{2}{*}{ thitung } & \multicolumn{2}{|c|}{ ttabel } \\
\hline & & & $\alpha=0,05$ & $\alpha=\mathbf{0 , 0 1}$ \\
\hline ry 2 & 0,415 & $4,33 * *$ & 1,95 & 2,64 \\
\hline ry 2.1 & 0,333 & $3,334 * *$ & 1,95 & 2,64 \\
\hline
\end{tabular}

Keterangan:

$* *=$ Regresi sangat signifikan, thitung $>$ ttabel pada $\alpha=0,01(4,33>2,64)$ thitung $>$ tabel pada $\alpha=0,01(3,334>2,64)$ 
Hubungan antara Supervisi dan Komunikasi

\section{Interpersonal dengan Produktivitas Kerja}

Perhitungan lengkap regresi jamak dari variabel terikat produktivitas kerja didapat arah regresi b1 sebesar 0,493 X1 dan b2 sebesar 0,329 $\mathrm{X}_{2}$ serta konstanta a sebesar 17,641. Dengan demikian bentuk hubungan antara variabel bebas dengan variabel terikat tersebut dapat digambarkan oleh persamaan regresi $\hat{Y}=17,641+0,493 \mathrm{X}_{1}+0,329 \mathrm{X}_{2}$. Sebelum digunakan untuk keperluan prediksi persamaan regresi ini harus dilakukan uji keberartian regresi. Untuk mengetahui derajat keberartian persamaan regresi, dilakukan uji $\mathrm{F}$ hasilnya dapat ditelaah pada Tabel 4.7 berikut:

Tabel 4. 9. Uji Signifikasi Regresi Ganda $\hat{Y}=17,641+0,493$ X1 + 0,329 X2.

\begin{tabular}{|c|c|c|c|c|c|c|}
\hline \multirow{2}{*}{$\begin{array}{l}\text { Sumber } \\
\text { Variasi }\end{array}$} & \multirow{2}{*}{ dk } & \multirow{2}{*}{ JK } & \multirow[b]{2}{*}{ RJK } & \multirow{2}{*}{ F hitung } & \multicolumn{2}{|c|}{$\mathbf{F}$ tabel } \\
\hline & & & & & $\alpha=0,05$ & $\alpha=0,01$ \\
\hline Total & 91 & $16.579,478$ & & & & \\
\hline JK (reg) & 2 & $5.339,539$ & $2.669,769$ & $21,13 * *$ & 3,097 & 4,66 \\
\hline JK(S) & 89 & $11.239,939$ & 126,291 & & & \\
\hline
\end{tabular}

Keterangan:

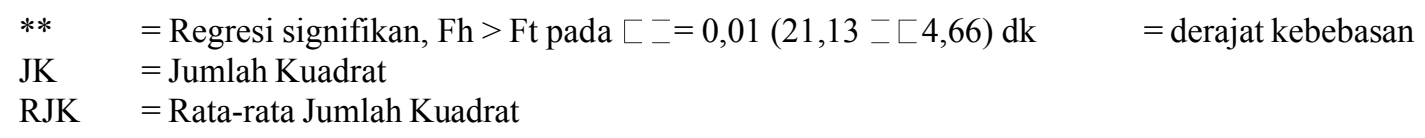

Perhitungan korelasi ganda antara $\mathrm{X}_{1}$ dan $\mathrm{X}_{2}$ dengan $\mathrm{Y}$ menghasilkan koefisien korelasi sebesar $\mathrm{R}$ $=0,567$. Uji keberartian dengan menggunakan uji $\mathrm{F}$ sebesar Fhitung $=21,13$. Untuk lebih jelasnya mengenai hubungan $\mathrm{X} 1, \mathrm{X} 2$ dengan $\mathrm{Y}$ dapat dilihat pada Tabel 4. 10 berikut:

Tabel 4.10. Rangkuman Uji Korelasi Jamak antara X1,X2 dengan Y

\begin{tabular}{|l|c|c|c|c|}
\hline \multirow{2}{*}{ Korelasi } & \multirow{2}{*}{ F } & \multirow{2}{*}{ Fhitung } & \multicolumn{2}{|c|}{ Ftabel } \\
\cline { 4 - 5 } & & & $\boldsymbol{\alpha}=\mathbf{0 , 0 5}$ & $\boldsymbol{\alpha}=\mathbf{0 , 0 1}$ \\
\hline $\mathrm{R}_{\mathrm{y} .12}$ & 0,567 & $21,13^{* *}$ & 3,097 & 4,66 \\
\hline
\end{tabular}

Keterangan :

$* *=$ Korelasi signifikan $(\mathrm{Fh}=21,13>\mathrm{Ft}=4,66) \mathrm{Ry} .12$

Dari hasil pengujian signifikansi regresi ganda seperti pada Tabel 4.10 dapat disimpulkan bahwa koefisien korelasi jamak yang diperoleh dalam penelitian ini sangat signifikan. Dengan demikian dapat dikatakan bahwa hipotesis yang menyatakan terdapat hubungan positif antara supervisi dan komunikasi interpersonal secara bersama- sama dengan produktivitas kerja, teruji kebenarannya.

Koefisien determinasi adalah sebesar $\mathrm{R}^{2}=(0,567)^{2}$ $=0,322$. Ini menunjukkan bahwa 32,2\% variasi yang
= Korelasi X1, X2 dengan Y

terjadi pada produktivitas kerja dapat dijelaskan oleh supervisi dan komunikasi interpersonal melalui regresi $\hat{\mathrm{Y}}=17,641+0,493 \mathrm{X} 1+0,329 \mathrm{X} 2$.

Berdasarkan hasil analisis korelasi parsial pada pembahasan di atas dapat diketahui bahwa masingmasing variabel bebas mempunyai hubungan yang signifikan terhadap variabel terikatnya yaitu produktivitas kerja. Namun untuk mengetahui peringkat hubungan tersebut maka secara ringkas dapat dilihat pada tabel berikut: 
Tabel 4.11. Analisis Korelasi Parsial

\begin{tabular}{cccc} 
Korelasi & Dikontrol & Koefisien Korelasi & Peringkat \\
\hline $\mathrm{X} 1$ dengan $\mathrm{Y}$ & $\mathrm{X} 2$ & 0,459 & Pertama \\
\hline $\mathrm{X} 2$ dengan $\mathrm{Y}$ & $\mathrm{X} 1$ & 0,333 & Kedua
\end{tabular}

\section{PEMBAHASAN}

Berdasarkan hasil pengujian persyaratan analisis data dan pengujian hipotesis diperoleh bahwa hipotesis yang diajukan dalam penelitian ini diterima. Hal ini berarti terdapat hubungan langsung yang positif antara varabel-nariabel produktivitas kerja, supervisi dengan komunikasi interpersonal. Untuk lebih jelasnya hasil analisis dan pengujian hipotesis tersebut dapat dijelaskan sebagai berikut:

Pertama Supervisi terbukti mempunyai hubungan yang positif dengan produktivitas kerja dengan koefisien korelasi $\mathrm{r}_{\mathrm{y} 1}$ sebesar 0,549 dengan nilai $\mathrm{t}$ hitung $(6,23)>\mathrm{t}$ tabel $(2,63)$ pada $\alpha=0,01$. Hal ini menguatkan teori yang di kemukakan oleh Hawkins and Robin (2006: 6) menyatakan, "supervisor is to monitor the supervisee's conduct to ensure that appropriate and ethical professional practices are implemented leading to the best possible clilnical outcome for the client". Supervisor melakukan pemantauan terhadap kegiatan supervisi guna memastikan bahwa karyawan/pegawai bekerja secara professional yang tepat dan beretika professional yang mengarah ke hasil yang sebaik mungkin bagi klien.

Terdapatnya hubungan yang positif tersebut, mengandung pengertian bahwa semakin sering supervisi yang dilakukan oleh kepala BLKPI atau supervisor, maka produktivitas kerja pegawai akan semakin baik. Supervisi memberikan kontribusi terhadap produktivitas kerja sebesar 30,1\% . Supervisor mempunyai tugas yang salah satunya meningkatkan produktivitas kerja pegawai. Apabila supervisor melaksanakan fungsi supervisinya secara terprogram dan terencana, maka produktivitas kerja pegawai akan semakin meningkat, karena aktifitas yang dilakukannya diawasi oleh atasannya baik secara langsung maupun tidak langsung. Tetapi sebaliknya apabila supervisor tidak melaksanakan fungsinya secara baik dan benar pada pegawai, maka produktivitas kerja pegawai akan menurun dengan adanya supervisi, maka seorang pegawai akan bekerja dengan penuh kesungguhan karena diawasi oleh atasannya. Selain itu seorang pegawai akan mengadmisnistrasikan semua hasil pekerjaannya sebagai bukti fisik bahwa ia telah melaksanakan tugas pekerjaan yang menjadi tanggung jawabnya. Dimana bukti fisik tersebut dijadikan sebagai bahan laopran secara tertulis.

Supervisi yang dilakukan atasan berguna untuk mencegah tindakan ketidak disiplinan dalam melaksanakan tugas sehingga akan menurunkan produktivitas kerja, sebagaimana yang di kemukakan oleh Donald C. Moesley et.al (2005: 440) "supervisors can take to increase productivity including upgrading workers'skills through training, improving worker motivation, using machinery and equipment better, improving quality, and preventing accident."

Dari teori di atas dapat dijelaskan bahwa supervisor memegang peranan penting dalam meningkatkan produktivitas kerja pegawai, motivasi dari supervisor juga sangat diperlukan dan akan sangat mempengaruhi produktivitas kerja bawahan, karena akan mempengaruhi kualitas kerja.

Kedua Terdapat hubungan yang positif antara komunikasi interpersonal dengan produktivitas kerja. Kekuatan hubungan antara komunikasi interpersonal dengan produktivitas kerja ditentukan oleh koefisien korelasi ry2 sebesar 0,415 dengan nilai t hitung (4, 33) $>\mathrm{t}$ tabel $(2,63)$ pada $\alpha=0,01$. Hal ini berarti kenaikan satu satuan unit komunikasi interpersonal akan 
diikuti oleh produktivitas kerja sebesar 0,463 satuan pada konstanta 51,41 .

Semakin baik komunikasi interpersonal, maka semakin tinggi pula tingkat produktivitas kerja pegawai. Hasil penelitian ini menguatkan teori yang di kemukakan oleh Robbins (2006: 409) yang menyatakan bahwa:

There is evidence that demonstrates a positive relationship between effective communication (which includes factors such as perceived trust, perceived accuracy, desire for interaction, top management receptiveness, and upward information requirements and worker productivity)"

Terdapat hubungan yang positif antara komunikasi yang efektif menganut faktor kepercayaan yang dianut, kecermatan yang dirasakan, keinginan untuk berinteraksi, kemauan menerima dari manajemen puncak, dan persyaratan informasi ke atas dengan produktivitas kerja. Dengan adanya komunikasi yang efektif, adanya kepercayaan antara pegawai dan saling terbuka akan memberikan dampak yang positif dalam organisasi, dengan adanya komunikasi yang baik maka akan meningkatkan kinerja pegawai artinya produktivitas kerja pegawai baik pula. Komunikasi antar pegawai harus tetap ditegakkan agar tidak terjadi miscommunication yang akan menghambat jalannya kelancaran organisasi. Jika produktivitas digabungkan di dalam suatu organisasi, produktivitas merupakan sarana untuk memonitor kemajuan, mengadakan umpan balik, menetapkan tujuan yang dapat diukur, dan mengevaluasi kinerja manajerial yang dilaksanakan oleh seorang pemimpin. Komunikasi antara pimpinan dan bawahan dimana manajemen juga harus mendengarkan karyawan. Seperti pendapat yang diungkapkan oleh Kinicki-Kreitner (2008: 309)

"Some communication experts contend that listening is the keystone communication skill for employees involved in sales, customer service, or management. In support of this conclusion, listening effectiveness was positively associated with customer satisfaction and negatively associated with employee intentions to quit".

Ketiga hubungan langsung supervisi, komunikasi interpersonal dengan produktivitas kerja. Terdapat hubungan yang positif antara supervisi, komunikasi interpersonal dengan produktivitas kerja. Hubungan yang cukup signifikan tersebut diketahui dari perhitungan korelasi ganda antara variabel supervisi dan variabel komunikasi interpersonal dengan produktivitas kerja yang menghasilkan koefisien korelasi R sebesar 0,567.

Hasil uji keberartian yang menggunakan uji $\mathrm{F}$ menghasilkan F hitung sebesar 21,13. Dari hasil pengujian signifikansi regresi ganda diatas didapat hubungan yang sangat signifikan. Koefisien $\mathrm{R}^{2}=$ $(0,567)^{2}=0,322$ menunjukkan bahwa $32,2 \%$ variasi yang terjadi pada produktivitas kerja berhubungan dengan supervisi dan komunikasi interpersonal.

Hasil penelitian ini mendukung pendapat yang dikemukakan Cherrington dalam jurnal Susan Fowler Fouts (2004: 42)

"Communicate clear expectations about productivity and high-quality crafmanship. Supervisors, peers and subordinates have clear expectations of performance. These expectations often become selffulfilling prophecies. Additionally, performance expectations are effectively communicated during the assignment of regular tasks and especially during the orientation of new employees. This communications includes teaching and explaining the values of work the dignity of labor, and the joy of service.

Komunikasi yang jelas diduga berkisar antara produktivitas dan keahlian yang berkualitas tinggi. Supervisor, rekan kerja serta bawahan mempunyai ekspektasi kinerja. Ekspektasi tersebut bahkan menjadi acuan penyelesaian bagi dirinya sendiri. Komunikasi ini mencakup pengajaran dan penjelasan nilai-nilai martabat kerja karyawan, dan kesenangan dalam bekerja. Bila pegawai merasa nyaman dan senang dalam bekerja dikarenakan komunikasi antar pegawai juga terjaga dengan baik makan akan menghasilkan 
dampak yang baik otomatis produktivitas juga meningkat.

Fungsi pengawasan yang dilakukan oleh manajer atau pimpinan kepada tim kerjanya yaitu pegawai, sangat diperlukan untuk kelangsungan organisasi. Suatu organisasi harus mengadakan interaksi antar pegawai maupun pimpinannnya. Komunikasi yang inten harus dilakukan terus menerus. Tanpa ada komunikasi pegawai tidak akan tahu apa yang sedang terjadi, manajemen tidak dapat menerima informasi dan sebaliknya, supervisor tidak dapat memberi instruksi. Komunikasi membantu menyelesaikan semua fungsi manajemen dasar, yaitu: planning (perencanaan), organizing), leading (kepemimpinan, controlling (pengawasan), sehingga organisasi dapat mencapai tujuannya.

Pengawasan (supervisi) yang dilakukan oleh manajer kepada bawahannya bertujuan agar tercapai suatu hasil kerja yang maksimal secara effektif dan efesien, memperbaiki kesahalan bawahan sedini mungkin, dan meningkatkan kerja tim. Semakin baik tingkat pengawasan yang dilakukan pimpinan kepada bawahan, maka pegawai akan melaksanakan kerja secara tertib dan efektif, yang berati terciptanya suatu produktivitas yang tinggi dalam melaksanakan suatu pekerjaan. Seperti yang diungkapkan oleh Garry Yukl (2010: 107) "The effective managers were also supportive and helpful with subordinates. Supportive behaviors that were correlated with effective leadership included showing trust and confidence, acting friendly and considerate, trying to understand subordinate problems, helping to develop subordinates and further their careers, keeping subordinate informed, showing appreciation for subordinates' ideas, allowed considerably autonomy in how subordinates so the work".

Pemimpin/manajer yang efektif juga mendukung dan membantu bawahanya. Sikap mendukung yang berkaitan dengan kepimpinan yang efektif mencakup dengan menunjukkan kepercayaan dan bersikap ramah terhadap pegawai, memahami masalah bawahan, membantu mengembangkan karir bawahan, selalu menyampaikan informasi, menghargai ide bawahan, dan membiarkan bawahan mempunyai otonomi dalam bekerja. Supervisor yang dekat dengan para pegawai akan menimbulkan kesan yang mendalam dalam menciptakan suasana kerja yang kondusif, menciptakan situasi kerja yang bergairah dan bersemangat.

\section{SIMPULAN}

Semangat kerja akan menimbulkan disiplin bagi para pegawai, sehingga meskipun supervisor tidak berada ditempat kerja atau meninggalkan tempat kerja untuk suatu keperluan, karyawan akan tetap melakukan pekerjaan dengan penuh tanggung jawab dan akan tetap bekerja dengan produktif. Suasana yang demikian akan terjadi apabila hubungan antara supervisor dengan para pekerja (pegawai) terjalin secara harmonis dengan dukungan komunikasi antar pegawai yang baik.

\section{DAFTAR RUJUKAN}

Carol A. Falender and Edward P. Shafranske, 2004.Clinical Supervision A Competency-Based Approach, Washsington, American Psychological Association.

Donald C. Moesly, Leon C. Megginson, Paul H. Pietri, 2005. Supervisory Management, South-Western, Thomson.

FX.Suwarto, 1999. Perilaku Keorganisasian, Yogyakarta, Universitas Atma Jaya.

Fred Luthans, 1992. Organizational Behavior, New York, Mc.Graw-Hill, Inc.

Gibson, Ivancevich dan Donnely, 1995. Organization Behaviors, Structure, Process. USA, Business, Publications, INC. fith edition. 
GR. Terry dan L.W. Rue, 2009. Dasar-Dasar Manajemen, alih bahasa- GA Ticoalu, Jakarta, Bumi Aksara.

Hadari Nawawi, 1983. Administrasi Pendidikan, Jakarta, Gunung Agung.

Herjanto, Eddy, 1999.Manajemen Produksi dan Operasi, Jakarta, PT Gramedia Widia Sarana Indonesia, Edisi kedua.

Kinicki and Kreitner, 2008. Organizational Behavior,Key Concepts, Skills and Best Practices Third Edition, New York, Mc GrawHill, Inc

Jerald Greenberg and Robert A. Baron, 2008. Behavior in Organizations, Ninth Edition, New Jersey, Pearson Education, Inc

John W, Newstrom, Keith Davis, 2002. Organizational Behavior, New York, Mc. Graw-Hill.

Joseph Propopenko, 1987. Productivity Management, A Practical handbook : International Labour Organization.

Made Pidarta, 2009. Supervisi Pendidikan Kontekstual, Jakarta: PT. Rineka Cipta.

Mucharsyah Sinungan, 2005. Produktivitas, Apa dan Bagaimana, Jakarta, Bumi Aksara.

Mullins Laurie J, 2005. Management and Organizational Behaviour, Edinburgh Gate, Prence Hall Financial Times.

Mc. Shane and Glinow, 2008. Organizational Behavior, Fourth Edition, New York, Mc.Graw-Hill, Inc

Mukhtar dan Iskandar, 2009. Orientasi Baru Supervisi Pendidikan, Jakarta: Gaung Persada Press.

Ngalim Purwanto, 2008. Administrasi dan Supervisi Pendidikan, Bandung: PT. Remaja Rosdakarya.

Onong Uchjana, 1987. Human Relations dan Public Relations dalam Manajemen, Bandung: Alumni.

Piet A. Sahertian, 2008. Konsep Dasar dan Teknik Superviso Pendidikan Dalam Rangka
Pengembangan Supervisi Pendidikan, Jakarta, PT Rineka Cipta.

Robert Kreitner, Angelo kinicki, 2007. Organizational Behavior, New York, The Mc. Graw-Hill, 2007.

Robbin, Stephen, Timothy A. Judge, organizational Behavior; New York, Prentice Hall

Robbin, Stephen, 2006. Perilaku Organisasi, Jakarta, PT. Indeks, edisi kesepuluh

Roberth L.Mathis, John H. Jackson, 2001. Manajemen Sumber Daya Manusia, Jakarta, PT Salemba Emban Patria, edisi pertama.

Schermerhorn, 2005. Management, New York, John Wiley \& Sons, Inc

Sergiovani dan Starrat, yang dikutip oleh E. Mulyasa, 2003. Menjadi Kepala Sekolah Profesional, Bandung, PT. Rosda Karya.

Sedarmayanti, 2009. Sumber Daya Manusia dan Produktivitas Kerja, CV Mandar Maju.

Sedarmayanti. Tata Kerja dan Produktivitas Kerja, 1999. CV. Mandar Maju.

Sulthon, 2009. Membangun Semangat Kerja Guru, Yogyakarta: LaksBang Pressindo.

Sondang P. Siagian, M.P.A, 2002. Kiat Meningkatkan Produktivitas Kerja, Jakarta, PT.Rineka Cipta.

Sudjana, 2005. Metoda Statistika Edisi ke. 6, Bandung: Tarsito

Thomas J. Sergiovanni \& Robert J. Starratt, 2002. Supervision A Redefinition, New York, Mc GrawHill 